Saudi Journal of Oral and Dental Research

Abbreviated Key Title: Saudi J Oral Dent Res ISSN 2518-1300 (Print) |ISSN 2518-1297 (Online) Scholars Middle East Publishers, Dubai, United Arab Emirates Journal homepage: http://scholarsmepub.com/sjodr/

\title{
Assessment of Oral Bacterial Profile and Antibiogram of Patients Attending Dental Clinic of a Private Tertiary Hospital in Ogun State, Nigeria
}

\section{Seyi Samson Enitan ${ }^{1 *}$, Adeolu Sunday Oluremi ${ }^{1}$, John Okeleke Ochei ${ }^{1}$, Richard Yomi Akele ${ }^{2}$, Stanley Osahon} Usiobeigbe $^{1}$, Ileoma Emmanuel ${ }^{1}$, Comfort Bosede Enitan ${ }^{3}$, Rukayah Oluwapelumi Tajudeen ${ }^{1}$

${ }^{1}$ Department of Medical Laboratory Science, Babcock University, Ilishan-Remo, Nigeria
${ }^{2}$ Department of Medical Laboratory Science, Afe Babalola University, Ado-Ekiti, Nigeria
${ }^{3}$ Department of Pathology, Igbinedion University, Teaching Hospital, Okada, Nigeria

DOI: $10.36348 /$ sjodr.2020.v05i01.003

| Received: 04.01.2020 | Accepted: 11.01.2020 | Published: 15.01.2020

*Corresponding author: Seyi Samson Enitan

\section{Abstract}

Background: Oral and dental problem is common among many Nigerian populace. The human oral cavity is one of the most dynamic habitats for numerous bacterial species where they undergo intense interspecies competition to form multispecies biofilm structure. Aim: The present study was designed to assess the oral bacterial profile and antibiogram of Adult Patients receiving dental care at Babcock University Teaching Hospital (BUTH), Ilishan-Remo Ogun State. Methods: A total of 200 oral swab samples were collected from 200 consenting participants (100 males and 100 females). The oral swab samples were cultured on Blood agar, MacConkey agar and Mannitol salt agar and incubated at $37^{\circ} \mathrm{C}$. Gram staining, motility test and routine biochemical tests were done for the identification and characterization of the bacterial isolates. Antibiotic susceptibility testing was carried out using the disc diffusion method. Data obtained were analysed using SPSS Statistics software package (version 18.0). Results: The bacterial species isolated include: Streptococcus viridans, Staphylococcus epidermidis, Enterobacter spp, Streptococcus pyogenes, Enterococcus feacalis, Klebsiella pneumoniae, Staphylococcus aureus, and Escherichia coli. Out of the 288 bacterial isolates obtained, 139 $(65.5 \%)$ of the oral bacteria isolates were non-pathogenic in nature, while $69(34.5 \%)$ were pathogenic. The pathogenic organism with the highest percentage occurrence was Enterobacter spp (37.7\%), followed by Streptococcus pyogenes (24.6\%), Enterococcus feacalis (19.7\%), Klebsiella pneumoniae (9.8\%), Staphylococcus aureus $(4.9 \%)$ and the least being Escherichia coli (3.3\%). Most of the Gram positive bacteria were sensitive to Augmentin, Sulbactomas, Cefroxime, Ciprofloxacin, Levofloxacin, Erythromycin and Azithromycin; while most of the Gram negative bacteria were sensitive to Augumentin, Cefotaxime, Nalidixic acid, Nitrofurantoin and Gentamycin. Conclusion: Pathogenic bacteria capable of causing oral and dental problems exist in the oral cavity of Patients receiving dental care at BUTH with varied antibiotic susceptibility patterns. The outcome of this study underscored the importance of routine oral/dental checks, adequate oral/dental care and treatment of oral infection with appropriate antibiotics.

Keywords: Oral cavity, Dental problem, Oral infection, Oral bacteria isolates, Antibiogram, Risk factors.

Copyright @ 2020: This is an open-access article distributed under the terms of the Creative Commons Attribution license which permits unrestricted use, distribution, and reproduction in any medium for non-commercial use (NonCommercial, or CC-BY-NC) provided the original author and source are credited.

\section{INTRODUCTION}

The environment in the human oral cavity (water, nutrients, epithelial debris and as well as a moderate temperature) supports the growth and survival of a wide range of microorganisms, including bacteria, yeasts, viruses and occasional protozoans, with bacteria predominantly residing in the microflora [1]. The prominent bacteria commonly found in the mouth include several genera such as: Streptococcus, Lactobacillus, Lactococcus, Enterococcus, Staphylococcus, Corynebacterium, Veillonella and Bacteroids [2-4]. These numerous bacterial species undergo intense interspecies competition to form multispecies biofilm structure $[5,6]$.

The mouth's mucous membranes are often sterile at birth, but can be contaminated within $4-12$ hours by passing through the birth canal. After birth, Streptococcus viridians became the most prominent member of the oral cavity's resident flora and remained so for life [7]. The organism is thought to have originated in mother and birth attendants' respiratory tracts [8].

Aerobic and anaerobic Staphylococcus, Neisseriae, Moraxella catarrahalis, Diptheroids and 
occasionally Lactobacilli are added to the oral microbial flora early in life, before the eruption of the teeth [8]. When teeth begin to erupt, however, anaerobic spirochete species such as Prevotella species, in particular Prevotella melaninogenica, Fusobacterium species, Rothia species and Capnocytophage species, together with some anaerobic Vibros and Lactobacilli, are found in the oral cavity. Actinomyces species are usually present in tonsillae tissue and gingivae in adults along with this load of bacteria [9].

Oral and dental problem such as tooth decay, tooth erosion, tooth sensitivity, tooth ache, calculus, gingivitis, periodontitis and plaque is common among many and it has been associated with poor oral hygiene [10]. The dental plaque for instance is a dense, nonmineralized, complex mass of bacterial colonies that live in a gel-intermixing matrix and adheres to the tooth. It contains bacterial cells, salivary polymers and bacterial extracellular products. The dental plaque begins to accumulate within 24 hours without regular tooth brushing. The dental plaque has an extrapolysaccharide that surrounds it and protects it from the penetration of an antibiotic. Plaque accumulation can be stimulated by increased production of gingival cervical fluid that contains growth factors of various bacteria including Gram negative anaerobes such as Porphyromonas gingivalis, Prevotella melaninogenica and Fusobacterium nucleatum [3, 6, 11, 12].

Furthermore; enteric bacteria can pose a potential threat and danger to children with inadequate and poor toilet hygiene by penetrating the body through the mouth as a result of nail biting and can lead to various oral cavity infections [13-15]. Since oral health is integral to general health and is essential to the overall health and wellbeing of all individuals, the early identification of oral disease may contribute to the early diagnosis and treatment for a number of systemic diseases. It is therefore, important to determine the bacterial profile of the mouth and the antibiogram as panacea for treatment of oral diseases.

To the best of our knowledge, no work has been done on the assessment of oral bacterial profile and antibiogram of Adult Patients receiving dental Care at Babcock University Teaching Hospital, Ilishan-Remo Ogun State. Besides the need to determine the oral bacterial profile of dental patients, it is very important to determine the antibiotic sensitivity pattern of these oral bacterial pathogens due to emergence and reemergence of antibiotic resistance among bacterial population. This will guide empirical therapy for oral infection and dental problems. This will reduce the number of hospital visits, cost of treatment and risk of treatment failure. Also, identification of risk factors associated with oral infection and dental problems will be found very helpful in developing control and prevention programs aimed at reducing oral infection and dental problems.

\section{MATERIALS AND METHODS Study Design}

This is a cross-sectional descriptive study.

\section{Study Area}

This study was carried out among adult patients receiving dental care at Babcock University Teaching Hospital (BUTH), Ilishan-Remo, Ogun State. BUTH is a 300 bed space capacity private hospital and the only tertiary hospital in the community. While Ilishan-Remo community is one of the geo-political wards in Ikenne Local Government Area of Ogun State, situated in the tropical area of South-western part of Nigeria, coordinates $7^{\circ} 29^{\prime} 00^{\prime} \mathrm{N}, 2^{\circ} 55^{\prime} 00^{\prime \prime} \mathrm{E}$.

\section{Study Duration}

The study lasted for a period of 3 months (April-June, 2019).

\section{Study Population}

This cross-sectional institutional based study was carried out among adult patients receiving dental care at Babcock University teaching hospital, IlishanRemo, Ogun state. The population of patients receiving dental care on a monthly basis is about 250-275.

\section{Sample Size Calculation}

The Sample size for this study was calculated using the formula described by Pourhoseingholi et al., [16]:

$$
\mathrm{n}=\underline{\mathrm{Z}^{2} \times P(1-\mathrm{P})}
$$

\section{$d^{2}$}

Where,

$$
\begin{aligned}
& \mathbf{n}=\text { minimum sample size required } \\
& \mathbf{Z}=\text { confidence interval }(1.96) \\
& \mathbf{P}=\text { Prevalence rate of oral bacterial pathogens } \\
& \text { in a tested population } \\
& \mathbf{d}=\text { desired level of significance }(0.05)
\end{aligned}
$$

For the calculation, a 95\% confidence interval, a $\mathrm{P}$ value of 0.1379 , i.e, a prevalence rate of $13.79 \%$ for Streptococcus salivarius among dental caries patients from a previous study by Maripandi et al., [17], and margin of error (d) set at 0.05 was used to determine the minimum sample size required. To minimize errors arising from the likelihood of non-compliance, $10 \%$ of the sample size was added to give a final sample size of 200 .

\section{Sample Size}

A total of 200 oral swab specimens were collected from 200 consenting adult patients (100 male and 100 females) receiving dental care at Babcock University Teaching Hospital (BUTH), Ilishan-Remo, Ogun State.

\section{Ethical Approval}

Ethical approval was obtained from the Babcock University Health Research Ethics Committee 
(BUHREC) before the commencement of the study with ethical registration number: BUHREC328/19.

\section{Eligibility of Subjects \\ Inclusion Criteria}

Consenting adult patients attending Dental Clinic of Babcock University Teaching Hospital (BUTH), Ilishan-Remo, Ogun State, who are not on antibiotic therapy in the preceding two (2) weeks were randomly selected for the study.

\section{Exclusion Criteria}

Dental patients less than 18 years and those with history of antibiotic therapy in the preceding two weeks were excluded from the study.

\section{Consent}

Informed consent was obtained from each participant. The purpose and nature of the study, as well as the method of sample collection was explained to them properly. Afterwards, participants was requested to voluntarily complete the consent form in their own handwriting and endorsed by their signatures as proof of willingness to provide samples for the test. They were assured of the confidentiality.

\section{Data Collection}

Prior to specimen collection, demographic and clinical information of the participants were obtained using prepared questionnaires administered to the participants. Each questionnaire had a unique participant identification number (PIDN). The first part of questionnaires contained the bio data of the participants such as age, marital status, religion, gender, tribe and educational status. The second part included clinical data relating to oral hygiene which may lead to presence of oral bacteria.

\section{Sample Collection and Transportation}

Oral swab specimen was collected from the oral cavity (mouth) of each participant by inserting a sterile oral swab stick 1-2 inches into the mouth to gently swab the walls of the oral cavity including the oral mucosa, the teeth, area between the cheek and gum, as well as the tongue (if white patches are present) for one to two minutes. The swab stick was removed in an aseptic manner and corked properly immediately. The oral samples was immediately kept in a transport media (Stuarts), a semi-solid medium containing substances that can prevent the overgrowth of commensals and prevent the organism of interest from dying as a result of change of $\mathrm{pH}$ and enzyme activity. These were transported to the laboratory inside a sealed plastic bag attached to a filled questionnaire and process within 2 hours of collection. All samples were transported to the laboratory as soon as possible without delay and were processed on the same day of collection.

\section{Laboratory Analysis}

Oral Swab Culture

The oral swab sticks were streaked directly on Blood Agar, Chocolate Agar, MacConkey Agar and Mannitol salt agar plates and were incubated at $37^{\circ} \mathrm{C}$ for 18-24 hours.

\section{Identification of bacterial isolates}

Standard techniques (macroscopy and microscopy) as described by Ochei and Kolhatkar [18] were adopted for the identification of the bacterial isolates. Morphological features of the colonies such as the size, shape, texture, elevation, pigmentation, margin and opacity were noted and recorded. Gram staining technique was performed to demonstrate their shapes and arrangement. Their biochemical characteristics were determined by carrying out catalase test, coagulase test, oxidase test, indole production test, citrate utilization test and triple sugar iron test, Optochin sensitivity test, Bile solubility test, and Bacitracin sensitivity test.

\section{Determination of the Antibiotic Sensitivity Pattern of bacterial isolates}

The antibiotic sensitivity pattern of the bacterial isolates were determined using commercially prepared antibiotic disc of known concentration supplied by Optum Lab Nigeria according to the modified Kirby-Bauer disc diffusion technique described by Cheesbrough [19] and CLSI [20]. The antibiotic discs used for Gram positive bacteria include: Ciprofloxacin $(5 \mu \mathrm{g})$; Norfloxacin $(10 \mu \mathrm{g})$, Gentamicin

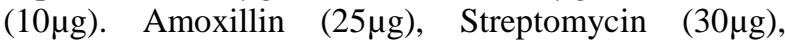
Rifampcin $\quad(5 \mu \mathrm{g}), \quad$ Erythronycin $\quad(15 \mu \mathrm{g})$, Chloramphenicol $(30 \mu \mathrm{g})$, Ampicillin / Cloxcicillin $(30 \mu \mathrm{g})$ and Levofloxacin $(5 \mu \mathrm{g})$. The antibiotic discs used for Gram negative bacteria include: Ofloxacin $(10 \mu \mathrm{g})$, Peflacine $(10 \mu \mathrm{g})$, Ciprofloxacin $(5 \mu \mathrm{g})$, Augmentin $(30 \mu \mathrm{g})$, Gentamicin $(10 \mu \mathrm{g})$, Streptomycin (30 $\mu \mathrm{g})$, Sulphamethazole/Trimethoprim (30 $\mu \mathrm{g})$, Ampicillin $(30 \mu \mathrm{g})$, Cephalexin $(30 \mu \mathrm{g})$ and Nalidixic acid $(30 \mu \mathrm{g})$. Appropriate control strains for each test isolate was used to test the performance of the method.

\section{Interpretation of zone sizes}

Using the Interpretative Chart, the zones sizes of each antibiotic were interpreted and the isolate reported as 'Resistant', 'Intermediate/Moderately susceptible', or 'Susceptible'.

\section{Determination of Multiple Antibiotic Resistant Index}

Multiple antibiotic resistance index (MARI) was determined to ascertain the number of antibiotics the isolates are resistant to according to the formula described by Akinjogunla and Enabule [21]:

MARI $=a / b$. 
Where;

$\mathbf{a}=$ number of antibiotics to which the isolate was resistant to;

$\mathbf{b}=$ total number of antibiotics to which the isolates was subjected to;

\section{STATISTICAL ANALYSIS}

Raw data was entered into Microsoft Excel. Statistical analysis was carried out using SPSS Statistics software package (version 18.0). Data obtained was analyzed statistically using Anova and Tukey-Kramer Multiple Comparisons Test. The level of significance was determined at $95 \%$. $\mathrm{P}$ values $<0.05$ will be considered significant.

\section{RESULTS AND DISCUSSION}

This present study assessed the oral bacteria profile and antibiogram of adult patients receiving dental care at Babcock University teaching hospital Ilishan-Remo, Ogun state, Nigeria. The sociodemographic characteristics of the study participants including gender, age range, marital status, religion, tribe and educational status is presented in Table-1. In all, a total number of 200 patients (100 females and 100 males) were assessed. Majority of the participants are within the age range of $18-27$ years $(64 \%)$, followed by 28-37years (14\%), 38-47years (10\%), 48-57years $(6.5 \%)$ and lastly 58 years and above $(5.5 \%)$. On the basis of religion, Christian participants were in majority (84\%), while Muslims participants were in minority (16\%). Most of the participants were Yorubas by tribe (82\%), followed by the Igbos (12.5\%), Hausas (3.0\%), and Others $(2.5 \%)$. Based on marital status, $66.5 \%$ were Singles, $33 \%$ were married and $0.5 \%$ were Divorced.

The frequency of bacteria isolation from the primary oral swab culture of the study Participants is presented using a pie chart (Figure-1). The number of mono- (1), dual- (2) and poly- (>2) bacteria isolation was $156(73.6 \%), 36(17 \%)$ and 20 (9.4\%), respectively. In all, a total of 288 oral bacterial isolates were identified, in which 197 (68.5\%) were nonpathogenic, while the remaining 91 (31.5\%) were pathogenic (Figure-2). The percentage of pathogenic oral bacterial isolates among the study participants was found to be significantly lower $(\mathrm{P}<0.05)$ than that of the non-pathogenic.

Furthermore, out of the 288 oral bacterial isolates, $242(84.1 \%)$ were Gram positive, while 46 (15.9\%) were Gram negative (Figure-3). The percentage of Gram positive oral bacterial isolates in the oral swab culture of the study Participants was found to be significantly higher $(\mathrm{P}<0.05)$ than that of Gram negative.

The frequency of the bacteria type recovered from the oral swab culture of the study Participants is presented in Table-2. In all, a total of eight (8) bacteria types were recovered: six (6) pathogenic (Staphylococcus aureus, Streptococcus pyogenes, Enterococcus feacalis, Escherichia coli, Klebsiella pneumoniae, and Enterobacter spp.) and two (2) nonpathogenic (Staphylococcus epidermidis and Streptococcus viridian. The pathogenic organism with the highest percentage occurrence was Enterobacter spp (7.9\%), followed by Enterococcus feacalis (5.9\%), Streptococcus pyogenes (5.2\%), Staphylococcus aureus (4.5\%), Escherichia coli $(4.2 \%)$, and the least being Klebsiella pneumoniae (3.8\%), On the other hand, the non-pathogenic organism with the highest percentage occurrence was Streptococcus viridans (62.9\%), while the lowest was Staphylococcus epidermidis (5.6\%).

Table-3 shows the risk factors associated with occurrence of oral bacteria among the study participants. $91(31.5 \%)$ of the pathogenic isolates were recovered from participants who visit the dental clinic only when there is a problem, $16(6.0 \%)$ were obtained from participants who had undergone surgery recently, $71(24.6 \%)$ were obtained from participants who brush their teeth once daily, $55(19.1 \%)$ were gotten from participants that change their tooth every 3 months, 27 $(9.3 \%)$ were obtained from participants that do not rinse their mouth after eating, $70(24.3 \%)$ were gotten from participants that do not check if their toothpaste contains fluoride. Still, $23(8 \%)$ of the pathogenic isolates were recovered from participants that engage in oral sex, $56(19.4 \%)$ and $8(2.7 \%)$ from participants that use conventional tooth paste and herbal tooth powder, respectively, as their Cleaning agent for oral hygiene. $68(23.6 \%)$ of the pathogenic isolates were obtained from participants that are in Possession of a case for keeping their tooth brush, 23.

Table-1: Socio-demographic characteristics of the study participants

\begin{tabular}{|l|l|l|l|}
\hline Characteristics & Category & Frequency & Percent \\
\hline \multirow{3}{*}{ Sex } & Male & 100 & 50.0 \\
\cline { 2 - 4 } & Female & 100 & 50.0 \\
\hline \multirow{5}{*}{ Age Range } & Total & 200 & 100 \\
\cline { 2 - 4 } & $18-27$ & 128 & 64.0 \\
\cline { 2 - 4 } & $28-37$ & 28 & 14.0 \\
\cline { 2 - 4 } & $38-47$ & 20 & 10.0 \\
\cline { 2 - 4 } & $48-57$ & 13 & 6.5 \\
\cline { 2 - 4 } & $\geq 58$ and above & 11 & 5.5 \\
\hline Religion & Total & 200 & 100 \\
\hline \multirow{5}{*}{ Tribe } & Christianity & 168 & 84.0 \\
\cline { 2 - 4 } & Islam & 32 & 16.0 \\
\hline & Total & 200 & 100 \\
\hline & Yoruba & 164 & 82.0 \\
\cline { 2 - 4 } & Igbo & 25 & 12.5 \\
\cline { 2 - 4 } & Hausa & 6 & 3.0 \\
\cline { 2 - 4 } & Others & 5 & 2.5 \\
\hline Education & Total & 200 & 100 \\
\hline & None & 2 & 1.0 \\
\cline { 2 - 4 } & Primary & 4 & 2.0 \\
\cline { 2 - 4 } & Secondary & 16 & 8.0 \\
\cline { 2 - 4 } & Tertiary & 178 & 89.0 \\
\hline & Total & 200 & 100 \\
\cline { 2 - 4 } & Single & 133 & 66.5 \\
\cline { 2 - 4 } & Married & 66 & 33.0 \\
\hline \multirow{5}{*}{ Marriage } & Total & 1 & 0.5 \\
\hline \multirow{5}{*}{} & & 200 & 100 \\
\hline
\end{tabular}

(C) 2020 | Published by Scholars Middle East Publishers, Dubai, United Arab Emirates 


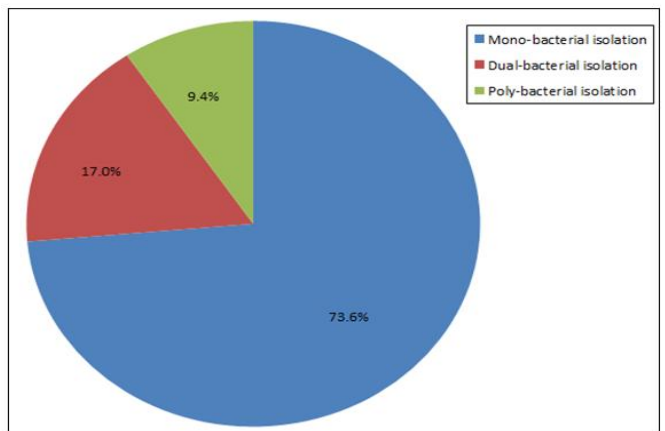

Fig-1: The frequency of bacteria isolation from the primary oral swab culture of the study Participants

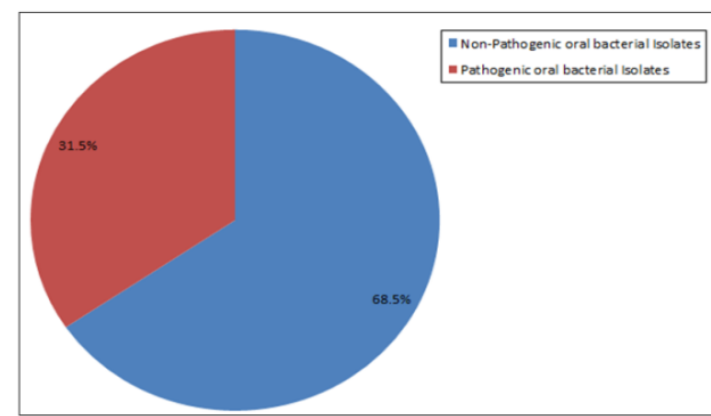

Fig-2: Frequency of occurrence of pathogenic and non-pathogenic bacterial isolates in the oral swab culture of the study Participants

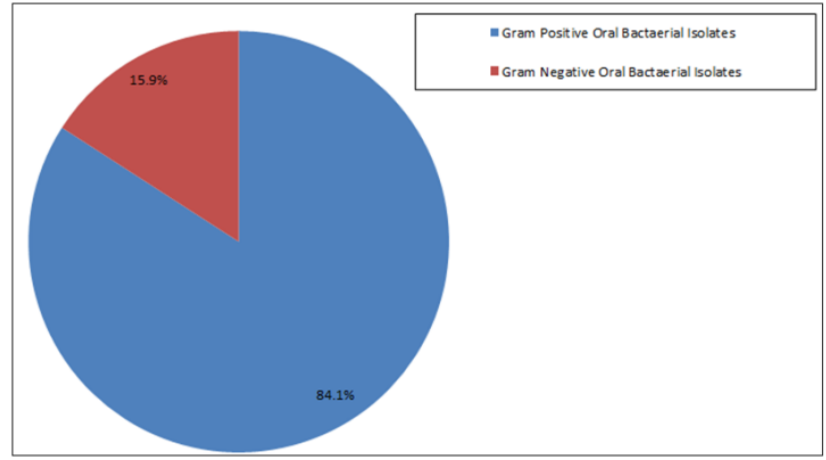

Fig-3: Frequency of occurrence of Gram positive and Gram negative oral bacterial isolates in the oral swab culture of the study Participants

Table-2: Frequency of the bacteria type recovered from the oral swab culture of the study Participants

\begin{tabular}{|l|l|l|}
\hline Bacteria type & Number of isolates $(\mathbf{N})$ & Percentage (\%) \\
\hline Pathogenic & & \\
\hline Enterobacter spp & 23 & 7.9 \\
\hline Enterococcus feacalis & 17 & 5.9 \\
\hline Streptococcus pyogens, & 15 & 5.2 \\
\hline Staphylococcus aureus, & 13 & 4.5 \\
\hline Escherichia coli, & 12 & 4.2 \\
\hline Klebsiella pneumoniae, & 11 & 3.8 \\
\hline Non-pathogenic & & \\
\hline Streptococcus viridians & 181 & 62.9 \\
\hline Staphylococcus epidermidis & 16 & 5.6 \\
\hline Total & 288 & 100 \\
\hline
\end{tabular}

(7.9\%) from participants that do not possess a case for keeping tooth brush. 19 (6.5\%) were obtained from participants that use mouth wash and 72 (25\%) from participants that do not use mouth wash.

The indications for oral and dental problem in relation to the occurrence of pathogenic and nonpathogenic oral bacterial isolates among the study participants are presented in Figure-4. Twenty five, 25 (12.5\%) pathogenic isolates were recovered from participants who complained of toothache, $8(4 \%)$ from those with swollen gums, $12(6 \%)$ from those who had bleeding gums, $8(4 \%)$ from those with stained teeth and another 8 (4\%) from those with oral sore. None $(0 \%)$ was recovered from those having bad breath.

The antibiotic sensitivity pattern of Gram positive bacterial isolates recovered from the oral cavity of dental patients is presented using a histogram (Figure-5). Streptococcus viridians was most sensitive to Ciprofloxacin and Cefixime (85.7\%), but least sensitive to Cefuroxime (4.8\%). Enterococcus feacalis was most sensitive to Augmentin and Levofloxacin (91.7\%), but least sensitive to Azithromycin (25\%). Furthermore, Streptococcus pyogenes was most sensitive to Augumentin (80\%), but least sensitive to Imipenem (0\%). Staphylococcus epidermidis on the other hand, was most sensitive to Augumentin, Sulbactomas, Erythromycin and Azithromycin (100\%), but least sensitive to Imipenem, Cefuroxime and Ofloxacin (0\%). Meanwhile, S. aureus was most sensitive to Augumentin and Sulbactomas (100\%), but least sensitive to Levofloxacin, Cefuroxime and Ofloxacin $(33.3 \%)$.

Similarly; the antibiotic sensitivity pattern of Gram negative bacterial isolates recovered from the oral cavity of dental patients is presented using a histogram (Figure-6). Klebsiella pneumoniae was most sensitive to Sulbactomas and Levofloxacin $(66.7 \%)$, but least 
Seyi Samson Enitan et al; Saudi J Oral Dent Res, Jan 2020; 5(1): 11-23

sensitive to Ofloxacin (0\%). Enterobacter spp was most sensitive to Levofloxacin (85.7\%), but least sensitive to Cefotaxime (0\%). Escherichia coli on the other hand was most sensitive to Augumentin, Cefotaxime, Nalidixic acid, Nitrofurantoin and Gentamycin (100\%), but least sensitive to Levofloxacin and Imipenem (0\%).

Lastly, the multiple antibiotic resistant index (MARI) of the oral bacteria isolates is presented in Table-4, ranging from 0-0.3. MARI for Staphylococcus aureus, Streptococcus viridians and Enterococcus feacalis was zero (0). Streptococcus pyogenes, Klebsiella pneumoniae and Enterobacter spp had 0.1 MARI, while Staphylococcus epidermidis and
Escherichia coli, both had 0.3 MARI. Values greater than 0.2 are considered to be clinical significantly.

On one hand, the number of oral bacterial isolates (288) recorded in this study was found to be slightly higher than the 282 recovered by Anejo-Okopi et al., [22] from patients with history of dental caries in Jos, Nigeria, but 2-5 times higher than the 45, 46, 58, 59, 74 and 150 recovered among dental patients and others in Dhaka-Bangladesh [23], Hail-Kingdom of Saudi Arab [24], Minna-Nigeria [25], Pahang-Malaysia [26], Tamilnadu-India [17], and Madhya Pradesh-India [27], respectively.

Table-3: Risk factors associated with the occurrence of oral bacteria pathogens among the study participants

\begin{tabular}{|c|c|c|c|c|c|c|c|c|}
\hline Characteristics & Response & $\begin{array}{l}\text { No. of study } \\
\text { participants }\end{array}$ & $\begin{array}{l}\text { No. of } \\
\text { Non- } \\
\text { Pathogenic } \\
\text { isolates N } \\
(\%)\end{array}$ & $\begin{array}{l}\text { No. of } \\
\text { Pathogenic } \\
\text { Isolates N } \\
(\%)\end{array}$ & $\begin{array}{l}\text { No. of } \\
\text { Isolates } \\
\mathbf{N}(\%)\end{array}$ & $\begin{array}{l}\text { P- } \\
\text { Value }\end{array}$ & OR & $\begin{array}{l}\text { Pearson } \\
\text { Chi- } \\
\text { Square } \\
\left(\chi^{2}\right)\end{array}$ \\
\hline \multirow{7}{*}{$\begin{array}{l}\text { Frequency of visit } \\
\text { to the dental } \\
\text { clinic }\end{array}$} & Monthly & $2(1)$ & $6(2.1)$ & $3(1.0)$ & $9(3.1)$ & 0.619 & 0.866 & 3.227 \\
\hline & Every 3 months & $5(2.5)$ & $7(2.4)$ & $7(2.4)$ & $14(4.8)$ & 0.411 & 3.899 & \\
\hline & Every 6 months & $18(9)$ & $17(5.9)$ & $11(3.8)$ & $28(9.7)$ & 0.934 & 0.906 & \\
\hline & Every 9 months & $9(4.5)$ & $10(3.5)$ & $8(2.8)$ & $18(6.3)$ & 0.773 & 0.775 & \\
\hline & Every 12 months & $13(6.5)$ & $13(4.5)$ & $5(1.7)$ & $18(6.3)$ & 0.999 & 1.002 & \\
\hline & $\begin{array}{l}\text { only when there is a } \\
\text { problem }\end{array}$ & $153(76.5)$ & $144(50)$ & $57(19.8)$ & $201(69.8)$ & 0.640 & 1.647 & \\
\hline & Total & $200(100)$ & $197(68.5)$ & $91(31.5)$ & $288(100)$ & & & \\
\hline \multirow{3}{*}{$\begin{array}{l}\text { Undergone dental } \\
\text { surgery recently }\end{array}$} & Yes & $31(15.5)$ & $43(15)$ & $16(6.0)$ & $59(20.5)$ & 0.268 & 1.435 & 1.227 \\
\hline & No & $169(84.5)$ & $154(53.5)$ & $75(26.0)$ & $229(79.5)$ & 0.136 & 0.434 & \\
\hline & Total & $200(100)$ & $197(68.5)$ & $91(31.5)$ & $288(100)$ & & & \\
\hline \multirow{4}{*}{$\begin{array}{l}\text { Frequency of } \\
\text { mouth brushing }\end{array}$} & Once daily & $161(80.5)$ & $145(50)$ & $71(24.6)$ & $216(75)$ & 0.548 & 0.953 & 3.179 \\
\hline & Twice daily & $34(117)$ & $42(15)$ & $20(6.9)$ & $62(21.5)$ & 0.999 & $458 \mathrm{E}$ & \\
\hline & Thrice daily & $5(2.5)$ & $10(3.5)$ & $0(0)$ & $10(3.5)$ & 0.997 & $804 \mathrm{~A}$ & \\
\hline & Total & $200(100)$ & $197(68.5)$ & $91(31.5)$ & $288(100)$ & & & \\
\hline \multirow{5}{*}{$\begin{array}{lr}\begin{array}{l}\text { Frequency } \\
\text { changing }\end{array} & \text { of } \\
\text { brush } & \text { tooth } \\
& \end{array}$} & Every 3 months & $124(62)$ & $104(36.1)$ & $55(19.1)$ & $159(55.2)$ & 0.972 & 0.811 & 3.393 \\
\hline & Every 6 months & $43(21.5)$ & $44(15.3)$ & $22(7.6)$ & $66(23)$ & 0.999 & $509 \mathrm{~A}$ & \\
\hline & Every 9 months & $28(14)$ & $36(12.5)$ & $14(4.8)$ & $50(17.3)$ & 0.999 & $493 \mathrm{~A}$ & \\
\hline & Never & $5(2.5)$ & $13(4.6)$ & $0(0)$ & $13(4.5)$ & 0.999 & $387 \mathrm{E}$ & \\
\hline & Total & $200(100)$ & $197(68.5)$ & $91(31.5)$ & $288(100)$ & & & \\
\hline \multirow{3}{*}{$\begin{array}{l}\text { Share tooth brush } \\
\text { with others }\end{array}$} & Yes & $0(0)$ & $0(0)$ & $0(0)$ & $0(0)$ & & & \\
\hline & No & $200(100)$ & $197(68.5)$ & $91(31 / 5)$ & $288(100)$ & & & \\
\hline & Total & $200(100)$ & $197(68.5)$ & $91(31.5)$ & $288(100)$ & & & \\
\hline \multirow{3}{*}{$\begin{array}{l}\text { Rinse mouth after } \\
\text { eating }\end{array}$} & Yes & $157(78.5)$ & $151(52.5)$ & $64(22.2)$ & $215(74.7)$ & 0.054 & 1.848 & 3.717 \\
\hline & No & $43(21.5)$ & $46(16)$ & $27(9.3)$ & $73(25.3)$ & 0.093 & 0.471 & \\
\hline & Total & $200(100)$ & $197(68.5)$ & $91(31.5)$ & $288(100)$ & & & \\
\hline \multirow{3}{*}{$\begin{array}{l}\text { Check if } \\
\text { toothpaste } \\
\text { contains fluoride }\end{array}$} & Yes & $36(18)$ & $45(15.5)$ & $21(7.2)$ & $66(22.9)$ & 0.582 & 1.062 & 0.302 \\
\hline & No & $164(82)$ & $152(53.0)$ & $70(24.3)$ & $222(77.1)$ & 0.339 & 1.588 & \\
\hline & Total & $200(100)$ & $197(68.5)$ & $91(31.5)$ & $288(100)$ & & & \\
\hline \multirow{2}{*}{$\begin{array}{l}\text { Engage in oral } \\
\text { sex }\end{array}$} & Yes & $13(6.5)$ & $0(0)$ & $23(8)$ & $23(8.0)$ & 0.146 & 0.341 & 26.397 \\
\hline & $\mathrm{No}$ & $187(93.5)$ & $197(68.5)$ & $68(23.5)$ & $265(132.5)$ & 0.998 & $518 \mathrm{H}$ & \\
\hline \multirow[t]{4}{*}{$\begin{array}{l}\text { Cleaning agent } \\
\text { for oral hygiene }\end{array}$} & $\begin{array}{l}\text { Conventional } \\
\text { Toothpaste }\end{array}$ & $147(71)$ & $141(49)$ & $56(19.4)$ & 197(68.4) & 0.743 & 1.206 & 0.427 \\
\hline & Herbal Toothpaste & $44(22)$ & $42(14.6)$ & $27(9.4)$ & $69(24)$ & 0.798 & 0.784 & \\
\hline & $\begin{array}{ll}\begin{array}{l}\text { Herbal } \\
\text { powder }\end{array} & \text { Tooth } \\
\end{array}$ & $9(4.5)$ & $14(4.9)$ & $8(2.7)$ & $22(7.6)$ & 0.932 & 1.090 & \\
\hline & Total & $200(100)$ & $197(68.5)$ & $91(31.5)$ & $288(100)$ & & & \\
\hline \multirow{3}{*}{$\begin{array}{l}\text { Possession of a } \\
\text { case for keeping } \\
\text { tooth brush }\end{array}$} & Yes & $165(82.5)$ & $155(54)$ & $68(23.6)$ & $223(77.4)$ & 0.717 & 1.058 & 0.131 \\
\hline & No & $35(17.5)$ & $42(14.5)$ & $23(7.9)$ & $65(21.9)$ & 0.829 & 1.109 & \\
\hline & & & & & & & & \\
\hline
\end{tabular}


Seyi Samson Enitan et al; Saudi J Oral Dent Res, Jan 2020; 5(1): 11-23

\begin{tabular}{|l|l|l|l|l|l|l|l|l|}
\hline & Total & $200(100)$ & $197(68.5)$ & $91(31.5)$ & $288(100)$ & & & \\
\hline \multirow{2}{*}{$\begin{array}{l}\text { Usage of mouth } \\
\text { wash }\end{array}$} & Yes & $28(14)$ & $39(13.5)$ & $19(6.5)$ & $58(20)$ & 0.777 & 1.092 & 0.08 \\
\cline { 2 - 9 } & No & $172(86)$ & $158(55)$ & $72(25)$ & $230(80)$ & 0.479 & 0.479 & \\
\hline
\end{tabular}

On the other hand, it was lower than the 294 and 325 reported by Khan et al., [28] and Yadav et al., [29] among dental caries patients in Gwalior-India and Nepal-India, respectively. The reasons for these variations can be accrue to the differences in the geographical regions, the methodology employed, as well as differences in the sample size and socioeconomic status of the study participants.

The percentage occurrence of Gram positive oral bacterial isolates $(84.1 \%)$ in the oral swab culture of the study Participants was found to be significantly higher $(\mathrm{P}<0.05)$ than that of Gram negative $(15.9 \%)$. This is in agreement with the work of Yadav et al. [29], who reported $91 \%$ and $9 \%$, respectively, and also that of Anejo-Okopi et al., [22], who reported $74.1 \%$ and $26.6 \%$ respectively. The above results therefore suggested that the micro-environments of the human oral cavity support the growth of more Gram positive bacteria than their Gram negative counterparts.

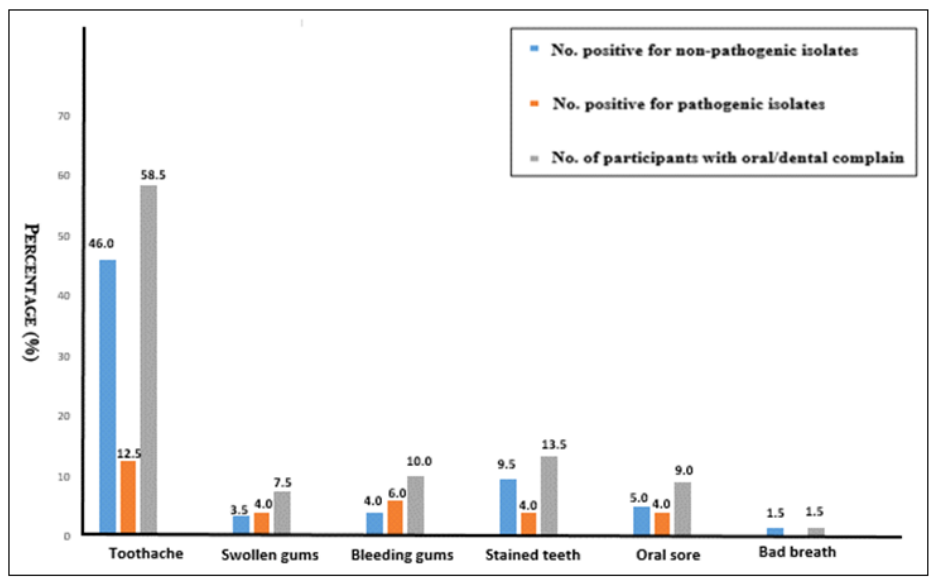

Fig-4: Histogram showing indications for oral and dental problem in relation to the occurrence of Pathogenic and non-pathogenic oral bacterial isolates among the study participants

Furthermore, the frequency of bacterial isolation from the primary oral swab culture of the Participants in this study differs from those of Ali et al., [26]. While $73.6 \%, 17 \%$ and $9.4 \%$ were recorded for mono-, dual- and poly- bacterial isolation, respectively, in this study, Ali and his Colleagues reported $55.9 \%$ and $44.1 \%$ for mono- and poly- bacterial isolation, respectively. There was no record of dual bacterial isolation in their study. The reason for this disparity is plausible and would require further investigation.

The oral bacterial profile observed in this current study partly agrees with those of previous studies. For instance, Daniyan et al., [25] reported only three (3) bacteria types: Staphylococcus aureus (53.4\%), as well as Streptococcus mutans (39.7\%) and Lactobacillus spp $(6.1 \%)$ which were not recorded in this study. Anejo-Okopi et al., [22] reported nine (9) bacteria types: Staphylococcus aureus (14.2\%), Klebsiella species (11.0\%), Escherichia coli $(7.1 \%)$ and Enterobacter species (2.5\%), as well as Lactobacillus species (28.4\%), Streptococcus mutans (18.0\%), Bacillus subtilis (13.5\%), Fusobacterium species (0.7\%) and Proteus mirabilis $(5.3 \%)$ which were not recorded in this study. Yadav et al. [29] also reported nine (9) bacteria types: S. aureus (28.92\%), K. pneumoniae (2.76\%), and Enterobacter spp. (1\%), as well as $S$. mutans (40\%), S. mitis (9.84\%), S. albus (7.38\%), S. vestibularis $(5.23 \%)$, Pseudomonas spp. (3.38\%), and $P$. vulgaris $(1.52 \%)$ which were not recorded in this study. In like manner, Saleem et al., [24] also reported nine (9) bacteria types: Staphylococcus aureus (19.6\%), Klebsiella species $(2.2 \%)$, as well as Streptococcus species (21.7\%), Pseudomonas species (19.6\%), Citrobacter species (10.9\%), Enterococcus faecium $(10.9 \%)$, Corynebacterium species $(6.5 \%)$, Neisseria species (6.5\%) and Enterococcus avium (2.2\%) which were not recorded in this study.

The above comparisons further strengthened the fact that the human oral cavity harbors and supports the growth of diverse, abundant and complex microbial community due to its warm environment which is rich in nutrients, continuous flow of saliva and a $\mathrm{pH}$ towards neutrality. This makes it an ideal place for the growth of vast array of bacteria, both pathogenic and nonpathogenic [32]. 


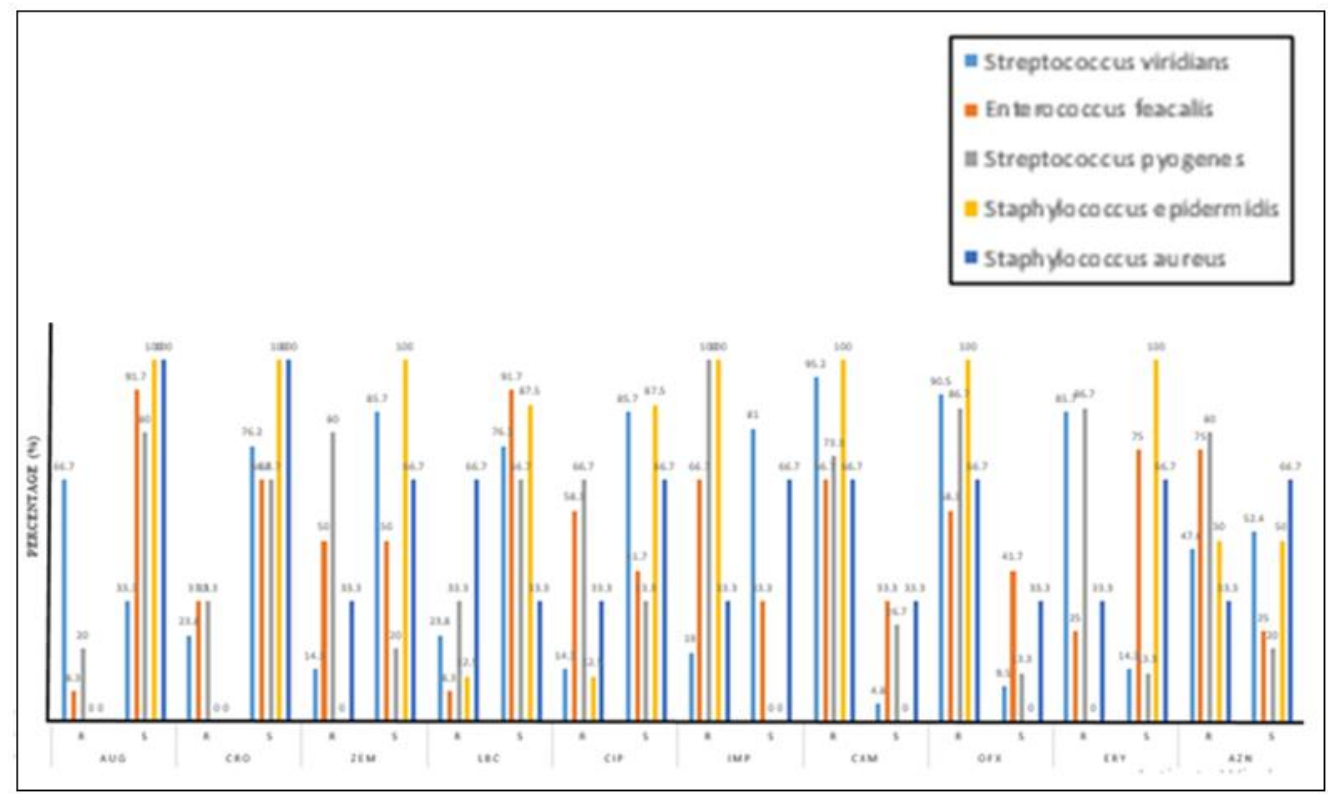

Fig-5: The antibiotic sensitivity pattern of Gram positive bacterial isolates recovered from the oral cavity of dental patients is presented using a histogram

Keys: $A U G=$ Augumentin, $C R O=$ Sulbactomas, $Z E M=$ Cefixime, $L B C=$ Levofloxacin, $C I P=$ Ciprofloxacin, IMP $=$ Imipenem, $C X M$ = Cefuroxime, $O F X=$ Ofloxacin, $E R Y=$ Erythromycin, $A Z N=$ Azithromycin

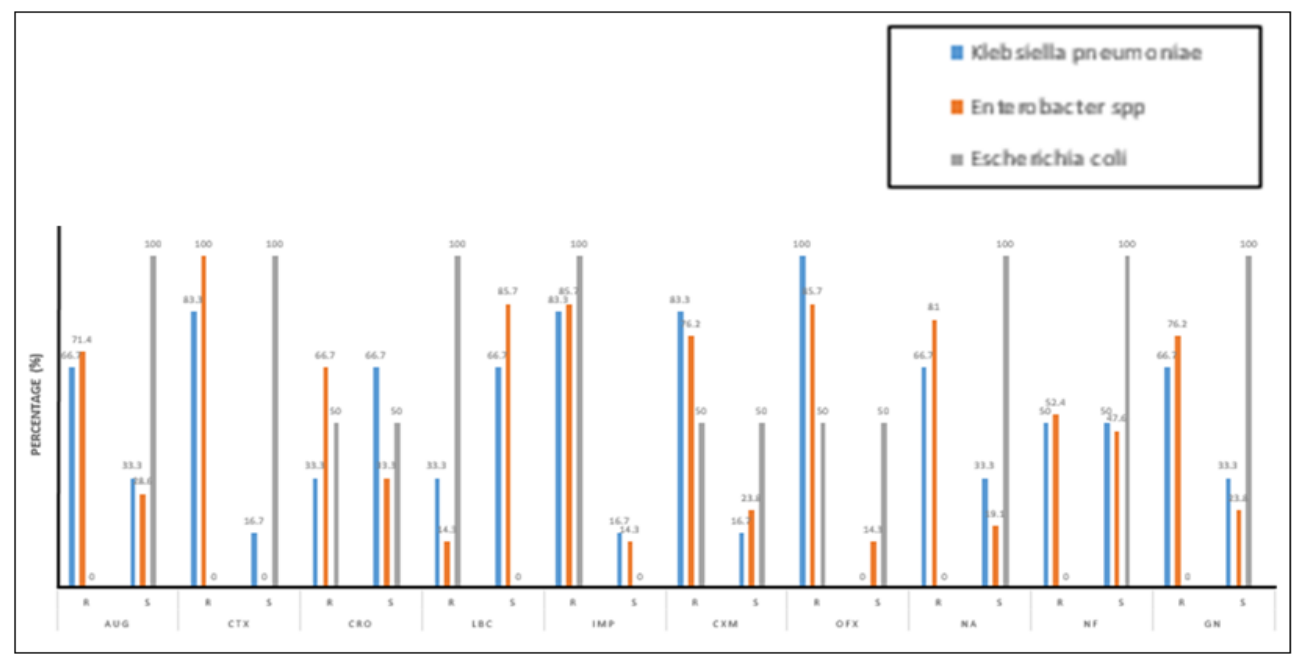

Fig-6: Antibiotic sensitivity pattern of Gram negative bacterial isolates recovered from the oral cavity of dental patients Keys: $A U G=$ Augumentin, CTX $=$ Cefotaxime, $C R O=$ Sulbactomas, $L B C=$ Levofloxacin, $I M P=$ Imipenem, CXM $=$ Cefuroxime, $O F X=$ Ofloxacin,$N A=$ Nalidixic acid, $\mathrm{NF}=$ Nitrofurantoin, $\mathrm{GN}=$ Gentamycin.

Table-4: Multiple Antibiotic Resistant Index of the oral bacteria isolates

\begin{tabular}{|l|l|l|l|}
\hline Type of Bacteria & $\begin{array}{l}\text { Number of antibiotics to which } \\
\text { the isolate was resistant to (a) }\end{array}$ & $\begin{array}{l}\text { Total number of antibiotics to which } \\
\text { the isolates was subjected to (b) }\end{array}$ & $\begin{array}{l}\text { MARI } \\
\text { (a/b) }\end{array}$ \\
\hline Staphylococcus aureus & 0 & 10 & 0 \\
\hline Staphylococcus epidermidis & 3 & 10 & 0.3 \\
\hline Streptococcus pyogenes & 1 & 10 & 0.1 \\
\hline Streptococcus viridians & 0 & 10 & 0 \\
\hline Enterococcus feacalis & 0 & 10 & 0 \\
\hline Escherichia coli & 3 & 10 & 0.3 \\
\hline Klebsiella pneumonia & 1 & 10 & 0.1 \\
\hline Enterobacter spp & 1 & 10 & 0.1 \\
\hline
\end{tabular}

NB: Multiple Antibiotic Resistant Index (MARI) $>0.2$ is considered to be clinical significantly. It indicates high risk source of contamination where antibiotics are often used [30, 31]. 
A remark on the natural habitats, modes of transmission and clinical significances of these bacteria will help in the understanding of their epidemiological roles. Staphylococcus aureus for instance is a normal flora of the nose and nasopharynx, but can be pathogenic when found outside the nasal region. Occurrence in the oral cavity is made possible when the individual sniffed back mucous from the nose to the mouth or after blowing the nose with bare hands and the hands are used to eat without proper washing. S. aureus can also easily be transferred through hand shaking as some persons are known to blow their nostrils with bare hands without washing either intentionally or unintentionally, which enhances the transmission of this organism from one person to another through hand shaking. The organism is endows with some virulence factors including coagulase, leukocidin, fibrinolysin, lipase, hyaluronidase and Protein A amongst others, which enables it to elicit so many attacks to the host causing infections including: mastitis, conjuctivitis, pimples, rashes, etc [33-35].

Staphylococcus epidermidis are usually carried on the skin of many healthy people and have been long referred to as not pathogenic, but their role as pathogens and vast increasing incidence rate have been recognized and studied of recent. This could be attributed to poor hygiene amongst the general populace. Most persons in Nigeria, do not always wash their hands thoroughly with soap and water after making use of the toilets, and even after eating or doing house chores and because human hands harbor a lot of pathogenic organisms even after proper hand washing and when not sanitized or washed properly, it becomes a good medium for transfer of microorganisms to various places, especially in the oral cavity of individuals $[34,36]$.

Streptococcus viridians are most abundant in the mouth and one member of the group A Streptococcus [37]. S. mutans, is the cause of dental caries in most cases and population [38]. S. sanguinis is also another potential cause. Others may be involved in other mouth or gingival infections as pericoronitis. If they are introduced into the bloodstream, they have the potential of causing endocarditis, in particular in individuals with damaged heart valves. They are the most common causes of sub-acute bacterial endocarditis. They have also been identified in cases of neonatal infections [34, 37, 39].

Streptococcus pyogenes is clinically important for humans. It is an infrequent, but usually pathogenic, part of the skin microbiota. S. pyogenes typically colonizes the throat, genital mucosa, rectum, and skins of healthy individuals, $1 \%$ to $5 \%$ have throat, vaginal, or rectal carriage. There are four methods for the transmission of this bacterium: inhalation of respiratory droplets, skin contact, and contact with objects, surface, or dust that is contaminated with bacteria or, less commonly, transmission through food $[34,35]$.
Enterococcus faecalis is a commensal bacterium inhabiting the gastrointestinal tracts of humans and other mammals. Like other species in the genus Enterococcus, E. faecalis is found in healthy humans, but can cause life-threatening infections, especially in the nosocomial (hospital) environment, where the naturally high levels of antibiotic resistance found in E. faecalis contribute to its pathogenicity. E. faecalis has been frequently found in re-infected, root canal-treated teeth in prevalence values ranging from $30 \%$ to $90 \%$ of the cases. Re-infected root canal-treated teeth are about nine times more likely to harbor $E$. faecalis than cases of primary infections $[4,34,35]$.

Enterobacter is a genus of common Gram negative, facultative anaerobic, rod-shaped, non-sporeforming bacteria of the family Enterobacteriaceae. They are found in the intestinal tract of humans and animals, and in soil, sewage, water, and dairy products. Several strains of these bacteria are pathogenic and cause opportunistic infection in immunocompromised (usually hospitalized) hosts and in those who are on mechanical ventilation. The urinary and respiratory tracts are the most common sites of infection. They are known to cause wound and blood infection. Contamination is largely responsible for their presence in the oral cavity $[34,35]$.

Klebsiella Pneumoniae is usually present in the respiratory tracts and faeces of about $5 \%$ of normal individuals. It causes chest infections and occasionally severe bronchopneumonia with lung abscesses. Klebsiella pneumoniae can produce extensive hemorrhagic necrotizing consolidation of the lungs. It can also cause urinary tract infection and bacteremia with focal lesion in debilitated patients. It is ranked among the top ten bacterial pathogens responsible for hospital- acquired infections, and is the second only to E. coli as a urinary tract pathogen [35]. K. pneumoniae has been implicated in oral infection because of its ability to degrade proteinaceous substances in the mouth resulting in bad breath [40].

The last, but not the least is Escherichia coli, a Gram negative motile organism, naturally found in the intestinal tract, but have been isolated from urine, pus, cerebrospinal fluid and blood in addition to fecal specimen. Strains of $E$. coli have been recognized to cause diarrhoeal diseases some of which include the enterotoxigenic $E$. coli, the enteropathogenic E. coli, the enteroinvasive $E$. coli and most recently the enterohaemorrhagic $E$. coli. The organism is the most pathogenic organism found in the urinary tract of man and is one of the major organisms that can cause infection of wounds in man and meningitis and bacteraemia in neonates [35]. And recently, E. coli has been incriminated in active caries lesions [41].

Regarding the indications for oral and dental problem in relation to the occurrence of pathogenic oral 
bacterial isolates among the study participants, $12.5 \%$ of the pathogenic isolates were recovered from participants who complained of toothache, $4 \%$ from those with swollen gums, $6 \%$ from those who had bleeding gums, $4 \%$ from those with stained teeth and another $4 \%$ from those with oral sores. These indications for oral and dental problem among the study participants with pathogenic isolates recovered from their oral swab culture is consistent with the earlier reports on the pathogenicity of these oral bacteria $[4$, $33,34,40]$.

Regarding the risk factors associated with the occurrence of oral bacteria pathogens among the study participants, the following were identified: poor oral hygiene and dental care, infrequent visit to the dental clinic, continuous use of tooth brush even when it is long overdue for a change, recent dental surgery, not rinsing the mouth after eating, engagement in oral sex, as well as poor hand/toilet hygiene. These and many more are consistent with the reports of Baydas et al., [13], Anejo-Okopi et al., [22], Saleem et al., [24] and Khan et al., [28].

It is said, "Prevention is better than cure". It is not a good practice to visit the dental clinic only when there is a problem. Ideally, one is expected to see his/her Dentist at least once in six (6) months for dental check-up and clean up to forestall the possibility of developing one dental problem or the other. This is part of preventive medicine. But, unfortunately, for many in the sub-Saharan countries like Nigeria, they see no reason to see their Dentists until when there is a problem, which most of the time they present very late, resulting in tooth extraction in most cases with some complication. This indifference to oral hygiene and dental care is largely due to ignorance and illiteracy, procrastination, lack of no time to visit the dental clinic, poverty or sheer negligence about personal health [42].

Furthermore, it has been recommended that one should change tooth brush once every 3 months, not necessarily when the bristles are bad. This is to avoid accumulation of microbial community which tend to form bio-films on the tooth brush with prolong usage. The reasons why many do not endorse this simple oral/dental hygiene practice are as earlier mentioned above. Another risk factor is history of recent dental surgery. As minor as tooth extraction is, the procedure exposes one's oral cavity to an array of exogenous bacteria which could be pathogenic in nature [43]. For this reason, standard best practices must be observed during dental procedure or oral intubation. These include the use of sterilized materials, tools and equipment. Failure in this regard, is responsible for most post-surgical infections. Another worrisome risk factor is the practice of oral sex among some folks. Pathogens from the vaginal of an infected female partner can be inoculated into the oral cavity of the male partner during oral sex; thus, pre-disposing the latter to oral infections.

Regarding the antibiotic susceptibility pattern of the oral isolates recovered from dental patients, the current work differ from those of Daniyan and Abalaka [25] who tested ten (10) antibiotics (Co-trimozazole, Fortum, Chloramphenicol, Rocephine, Claforan, Nitrofurantoin, Tetracycline, Ofloxacin, Zinnat and Gentamicin) against dental caries isolates and reported that Staphylococcus aureus was sensitive to Ofloxacin and Nitrofurantoin and totally resistant to Cotrimozazole and Erythromycin, whereas in this study, $S$. aureus was most sensitive to Augmentin and Sulbactomas and most resistant to Levofloxacin and Ofloxacin.

This study also varies from those of Maripandi et al., [17] who tested seven (7) antibiotics (Bacitracin, Penicillin, Streptomycin, Clindamycin, Chloroamphenicol, Vancomycin and Tetracyclin) also against dental caries isolates. Their results show that Streptococcus isolates were resistance to penicillin, but sensitive to tetracycline. Whereas in this study Streptococcus isolates were most resistant to Impinem and Ofloxacin and most sensitive to Augmentin and Sulbactomas.

This work further differs from those of AnejoOkopi et al., [22], who tested three (3) antibiotics (Erythromycin, Chloramphenicol and Vancomycin) against dental caries isolates. The result of their antibiotic susceptibility test revealed that Enterobacter species was resistant to all the three antibiotics used, whereas in this study, it was most resistant to Cefotaxime, Levofloxacin Ofloxacin. Their work further revealed that Staphylococcus aureus was resistant to erythromycin and vancomycin and most sensitive to chloramphenicol. Whereas in this study, it was most resistant to Ofloxacin, Levofloxacin and Cefuroxime and most sensitive to Augumentin and Sulbactomas.

On the other hand, it partly agrees with those of Yadav et al., [29] who tested nine (9) antibiotics against isolates recovered from dental caries patients. Among all the bacteria tested, the Gram positive isolates were found to be most sensitive to Ciprofloxacin, followed by Gentamicin and Erythromycin; whereas the Gram negative isolates were found to be more sensitive to Ciprofloxacin, followed by imipenem and gentamicin and ceftriaxone. In this study the Gram positive isolates were most sensitive to Augumentin, Sulbactomas, and Levofloxacin, but least sensitive to Imipenem, Cefuroxime and Azithromycin; whereas the Gram negative isolates were most sensitive to Augumentin, Nalidixic acid and Nitrofurantoin, but least sensitive to Ofloxacin, Levofloxacin and Imipenem. 
The outcome of this study show that Augumentin, Sulbactomas, Levofloxacin, Ciprofloxacin, Cefixime and Erythromycin are very potent and can be used for the effective treatment of oral and dental infections because of their bacteriostatic/bactericidal effects on the isolates considering the high level of sensitivity observed. Lack of sensitivity by some of the oral isolates to some of the antibiotics tested implies the emergence of antibiotic resistance in these organisms and this is largely due to indiscriminate use and abuse of these drugs. Therefore the practice of self-medication among many folks should be discouraged. Meanwhile antibiotic susceptibility testing using standard procedures should be done to ascertain the most effective drugs to guide empirical therapy [10].

Finally, this discussion will not be complete without a note on the multiple antibiotic resistance index (MARI) of the isolates. MARI was calculated by dividing the number of antibiotics to which the isolates were resistant over the total number of antibiotics to which the isolate was exposed as described by Apun et al., [44]. According to Mishra et al., [45], MAR index of 0.2 or higher indicates high risk sources of contamination, while MAR index of 0.4 or higher is associated with human faecal source of contamination. Thenmozhi et al., [46], also states that MAR index values $>0.2$ indicates existence of isolate from high risk contaminated source with frequent use of antibiotics, while values $\leq 0.2$ show bacteria from source with less antibiotics usage. High MAR indices mandate pharmaco-vigilant surveillance and remedial measures. In this study, E. coli and S. epidermidis having MAR index of 0.2 and above is worrisome. Therefore empirical treatment must be well guided by laboratory investigations through accurate antibiotic susceptibility testing [47].

\section{CONCLUSION}

Pathogenic bacteria capable of causing oral and dental problems exist in the oral cavity of Patients receiving dental care at BUTH, Ogun State, Nigeria with varied antibiotic susceptibility patterns. The outcome of this study underscored the importance of routine oral/dental checks, adequate oral/dental care and treatment of oral infection with appropriate antibiotics.

\section{REFERENCES}

1. Batabyal, B., Chakraborty, S., \& Biswas, S. (2012). Role of the oral micro flora in human population: A brief review. Int J Pharm Life Sci, 3:2220-2227.

2. Malekipour, M. R., Messripour, M., \& Shirani, F. (2008). Buffering Capacity of Saliva in Patients with Active Dental Caries. Asian J. Biochem., 3: 280-283.

3. Lewis, J. P. (2008). The Molecular Basis of HostPathogen Interaction in the Oral Cavity In:
Rogers, A. H. (ed.) Molecular Oral Microbiology

Book. Caister Academic Press, Australia. 292-300.

4. Wang Q. Q., Zhang, C. F., Chu, C. H., \& Zhu, X. F. (2012). Prevalence of Enterococcus faecalis in saliva and filled root canals of teeth associated with apical periodontitis. Int. J. Oral Sci. 4: 19-23.

5. Liu, W., Røder, H. L., Madsen, J. S., Bjarnsholt, T., Sørensen, S. J., \& Burmølle, M. (2016). Interspecific Bacterial Interactions are Reflected in Multispecies Biofilm Spatial Organization. Front. Microbiol., $\quad 7: 1366 . \quad$ doi: 10.3389/fmicb.2016.01366.

6. Dahlen, G., Basic, A., \& Bylund, J. (2019). Importance of Virulence Factors for the Persistence of Oral Bacteria in the Inflamed Gingival Crevice and in the Pathogenesis of Periodontal Disease. Journal of Clinical Medicine, 8(1339): 1-19.

7. Fábián, T., Hermann, P., Beck, A., Fejérdy P., \& Fábián, G. (2012) Salivary defense proteins: their network and role in innate and acquired oral immunity. Int J Mol Sci.13: 4295-4320.

8. Umar, M. Akafy, D. E., Abdulkarim, I. M., Yaya, A. A., \& Danasabe, Y. J. (2015). Biochemical characterization and antibiogram pattern of Streptococcus Mutans isolated from dental unit,Sick-Bay, Ahmadu Bello University, Zaria, Nigeria. Int J Bio Biomed Sci. 4:63-66.

9. Majumdar, S., \& Singh, A. B. (2014). Normal Microbial Flora of Oral Cavity. J Adv Med Dent Scien. 2(4): 62-66.

10. Haque, M., Sartelli, M., \& Haque, S. Z. (2019). Dental Infection and Resistance-Global Health Consequences. Dentistry Journal,7(22).

11. Daniluk, T., Tokajuk, G., Cylwik-Rokicka, D., Rozkiewicz, D., \& Zaremba, M. L. (2006). Aerobic and anaerobic bacteria in subgingival and supragingival plaques of adult patients with periodontal disease. Adv Med Sci., 51(1): 81-85.

12. Vesna, A. (2018). The Bacterial Flora in a Healthy Oral Cavity. Adv Dent \& Oral Health, 9(5): DOI: 10.19080/ADOH.2018.09.555773.

13. Baydas, B., Uslu, H., Yaruz, I., Ceylan, I., \& Dagsugu, J. M. (2007). Effect of chronic nail biting habit on the carriage of Enterobacteriaceae. J. Oral Microbiol and Immunol, 22: 1-4.

14. Jorge, A. O. C. (2007). Microbiologia bucal. (3th ed.) São Paulo: Santos.

15. Winn, W. C., Jr., Allen, S. D., Janda, W. M., Koneman, E. W., Procop, G. W., \& Schreckenberger, P. C. (2012). Koneman, diagnóstico microbiológico: texto e atlas colorido. Rio de Janeiro: Guanabara Koogan.

16. Pourhoseingholi, M. A., Vahedi, M., \& Rahimzadeh, M. (2013). Sample size calculation in Medical studies. Gastroenterology and Hepatology from Bed to Bench. 6(1): 14-17.

17. Maripandi, A., Arun, K. T., \& Al Salamah, A. A. (2011). Prevalence of dental caries bacteria pathogens and evaluation of inhibitory 
concentration effect on different tooth pastes against Streptococcus spp. African Journal of Microbiology Research, 5(14): 1778-1783.

18. Ochei, J., \& Kolhatkar, A. (2006). Identification Methods In: Ochei, J., Kolhatkar, A. (eds.). Medical laboratory science; Theory and Practice. Sixth Edition. Tata McGraw Hill Publishing Company. New Delhi, India. 644-658.

19. Cheesbrough, M. (2006). "Antimicrobial Susceptibility Testing” In: Cheesbrough, M. (ed.). District Laboratory Practice in Topical Countries, Part 2. Cambridge University Press, Cape Town, South Africa. 132-142.

20. CLSI. (2009). Performance standards for antimicrobial disk susceptibility tests In: Wayne, P. A. (ed.). Approved standard (15th ed.) of Clinical and Laboratory Standards Institute, 25(1): M02-A10.

21. Akinjogunla, O. J., \& Enabulele, I. O. (2010). Virulence Factors, Plasmid Profiling and Curing Analysis of Multidrug Resistant Staphylococcus aureus and Coagulase Negative Staphylococcus spp. isolated from Patients with Acute Otitis media. Journal of American Science, 6: 10221033.

22. Anejo-Okopi, J. A., Okwori, A. E. J., Michael, G., Okojokwu, O. J., \& Audu, O. (2015). Bacterial Profile Associated with Dental Caries in Jos, Nigeria. Advances in Research 4(6): 371-377.

23. Rahman, M., Islam, N., Islam, M. N., \& Hossain, M. S. (2015). Isolation and Identification of Oral bacteria and Characterization for bacteriocin Production and Antimicrobial Sensitivity. Dhaka University Journal of Pharmaceutical Sciences, 14(1): 103-109.

24. Saleem, M., Shahid, S. M. A., Kausar, M. A., Ahmed, M. Q., Ali, A. R., AlSogair, A., Alrashidi, A. A., Alharbi, A. A., \& Almansour, A. D. (2017). An Epidemiological Study of Bacterial Isolates from Oral Cavity of Medical Students and its Antimicrobial Resistance Pattern. J Cont Med A Dent., 5(2): 21-24.

25. Daniyan, S., \& Abalaka, M. (2011). Prevalence and susceptibility Pattern of Bacteria Isolates of Dental Caries in a Secondary Health Care Institution, Nigeria, Shiraz E-Med. J., 12(3): 135139.

26. Ali, M. J., Makky, E. A., Batool, T., \& Yusoff, M. M. (2015). Susceptibility of oral bacteria to antimicrobial agents and virulence factors $J$. Chem. Pharm. Res., 7(3): 1822-1829.

27. Deepak, D., Rakesh, K. P., Sapna, K., Tejram, K., Mukesh, K., Sarika, A., \& Vinod, S. (2015). Study of Molecular Mechanism of Antibiotic susceptibility against Polymicrobial Oral infection South Asian J Exp Biol., 1(1): 31-35.

28. Khan, A. A., Jain, S. K., \& Shrivastav, A. (2018). Isolation and Characterization of bacteria associated with dental caries with special references to their etiologic potential.
International Journal of Scientific Research in biological Sciences, 5(4): 87-91.

29. Yadav, K., Prakash, S., Yadav, N., \& Sah, R. (2015). Multi-Drug Resistance of Bacterial Isolates among Dental Caries Patients. Janaki Medical College Journal of Medical Sciences, 3(1): 37-44

30. Osundiya, O. O., Oladele, R. O., \& Oduyebo, O. O. (2013). Multiple Antibiotic Resistance (MAR) Indices of Pseudomonas and Klebsiella Species Isolates In Lagos University Teaching Hospital. Afr. J. Cln. Exper. Microbiol, 14(3): 164-168.

31. Nyandjou, Y. M. C., Yakubu, S. E., Abdullahi, I. O., \& Machido, D. A. (2019). Multidrug Resistance Patterns and Multiple Antibiotic Resistance Index of Salmonella species Isolated from Waste Dumps in Zaria Metropolis, Nigeria J. Appl. Sci. Environ. Manage, 23(1): 41-46.

32. Wan, N. H., Wan, I., Fathilah, A., \& Zubaidah, H. A. (2013). Oral microbes and its environment. Academic Journal, 9(2): 67-75.

33. Mehraj, J., Witte, W., Akmatov, M. K., Layer, F., Werner, G., \& Krause, G. (2016). Epidemiology of Staphylococcus aureus nasal carriage patterns in the Community. Curr Top Microbiol Immunol, 398: 55-87.

34. Brooks, G. F., Carroll, K. C., Butel, J. S., Morse, S. A., \& Mietzner, T. A. (2013). "Normal Human Microbiota. Lange Medical Book: Jawetz, melnick and Adelberg's Medical Microbiology (26 ${ }^{\text {th }}$ Ed.). McGraw-Hill Companies, Inc. United States, $165-$ 240.

35. Cheesbrough, M. (2006). "Features and Classification of Bacteria" In: Cheesbrough, M. (ed.). District Laboratory Practice in Topical Countries, Part 2. Cambridge University Press, Cape Town, South Africa. 18-20.

36. Ochei, J., \& Kolhatkar, A. (2006). Diagnosis of Infection by Specific Anatomical Site In: Ochei, J., Kolhatkar, A. (eds.). Medical laboratory science; Theory and Practice. Sixth Edition. Tata McGraw Hill Publishing Company. New Delhi, India. 615-643.

37. Beighton, D., Handle, J. M., \& Whiley, R. A. (1991). A scheme for the identification of viridans streptococci. Journal Med. Microbiol, 35: $367-$ 372.

38. Ranganathan, V., \& Akhila, C. H. (2019). Streptococcus mutans: has it become prime perpetrator for oral manifestations? Journal of Microbiology \& Experimentation, 7(4): 207-213.

39. Refoua, Y. (2005). A Study of Streptococcus viridans in the Maxillofacial Region. Frontiers in Dentistry, 2(4): 174-177.

40. Goldberg, S., Cardash, H., Browning, H., Sahly, H., \& Rosenberg, M. (1997). Isolation of Enterobacteriaceae from the mouth and potential association with malodor. Journal of Dental Research, 76(11): 1770-1775. 
41. Oztan, M. D., Kiyan, M., \& Gerceker, D. (2006). Antimicrobial effect, in-vitro, of gutta-percha points containing root canal medications against yeasts and Enterococcus faecalis. Oral Surg. Oral Med. Oral Pathol. Oral Radiol. Endod, 102(3): 410-416.

42. AL-Jawfi, K. A., \& Al-Mashhadani, A. M. (2018). Oral Health Knowledge, Attitudes and Practices among Secondary School Students in Sana'a City, Yemen. Saudi Journal Oral. Dent. Res., 3(7): 224230.

43. Bennadi, D. Varshini, K., Roy, P., Bharateesh, J. \& Kashinath, K. R. (2016) Assessment of oral health attitudes and behavior among undergraduate medical students using Hiroshima University Dental Behavioral Inventory HU-DBI. Saudi J. Oral. Dent. Res., 1(1): 7-10.

44. Apun, K., Chong, Y. L., Abdullahi, M. T., \& Micky, V. (2008). Antimicrobial Susceptibilities of Escherichia coli Isolates from Food Animals and Wildlife Animals in Sarawak, East Malaysia. Asian Journal Anim Vet Adv, 3(6): 409-416.

45. Mishra, M., Patel, A. K., \& Behera, N. (2013) Prevalence of Multidrug Resistant E. coli in the river Mahanadi of Sambalpur. Curr Res Microbiol Biotechnol., 1(5): 239-244.

46. Thenmozhi, S., Rajeswari, P., Suresh-Kumar, T., Saipriyanga, V., \& Kalpana, M. (2014). Multidrug Resistant Patterns of Biofilm Forming Aeromonas hydrophila from Urine Samples. Int. J. Pharm Sci Res. 5(7): 2908-2918.

47. Adenaike, O., Olonitola, O. S., Ameh, J. B., \& Whong, C. M. Z. (2016). Multidrug Resistance and Multiple Antibiotic Resistance Index of Escherichia coli Strains Isolated from Retailed Smoked Fish. Journal of Natural Sciences Research, 6(9): 18-27. 